\title{
Synaptic Transmission in Decentralized Axons of Rock Lobster
}

\author{
I. Parnas, ${ }^{1}$ J. Dudel, ${ }^{2}$ and H. L. Atwood ${ }^{3}$ \\ 'The Otto Loewi Center for Cellular and Molecular Neurobiology, The Hebrew University, Jerusalem 91904, Israel, \\ 2Physiologisches Institut der Technischen Universitat Munchen, D-8000 Munchen 40, Germany, and ${ }^{3}$ Department of \\ Physiology, University of Toronto, Toronto, Ontario, Canada M5S 1 A8
}

\begin{abstract}
Axons of the lobster deep abdominal extensor muscles were cut, and the resulting effects on their synaptic properties were observed. Decentralized axons continued to conduct action potentials and to release transmitter for at least a year after the cut. In controls, the single quanta were brief, and thelr decay phase could be fit by a single exponent, with a time constant of about 2 msec. Quanta of "cut axons" were slower, and their decay phase could not be fit by a single exponent. At midamplitude, the duration of the cutaxon quanta varied between 1.6 and $5.8 \mathrm{msec}$, as opposed to $0.6-2.8 \mathrm{msec}$ in controls. Synaptic delay histograms were taken as a measure of time course of evoked release. In controls, evoked release lasted less than $10 \mathrm{msec}$ at $14^{\circ} \mathrm{C}$. In cut axons, release lasted up to 10 times longer. The duration of release was not affected by tetrodotoxin, membrane depolarization, or hyperpolarization. It appears that the basic mechanism that controls the time course of evoked release is altered in degenerating terminals.
\end{abstract}

Crustacean neuromuscular systems with their relatively simple patterns of innervation (Atwood, 1976, 1977) are particularly suited to the study of problems related to synaptic plasticity (Atwood and Wojtowicz, 1986), compensatory mechanisms after removal of single neurons (Parnas and Bowling, 1977; Parnas et al., 1982; Dudel and Parnas, 1987), competition between neurons innervating the same target (Dudel et al., 1981; Parnas et al., 1984), and degeneration and regeneration (Hoy, 1969; Bittner and Johnson, 1974; Frank, 1974). The distal parts of severed axons do not degenerate rapidly in crayfish or lobster (Hoy et al., 1967) and continue to conduct action potentials and to release transmitter for at least a year after they are cut (Atwood et al., 1989). Astonishingly, satellite cells appear to invade the distal severed axons, where they lose their cell membranes to form a multinucleated structure (Atwood et al., 1989).

Although several studies report recording of synaptic potentials after stimulation of severed axons (Rotshenker, 1988), the properties of such synapses have not been investigated in detail. In the present study, we characterized synaptic properties of decentralized and normal axons in a lobster neuromuscular system. We compared conduction velocities, shapes of postsynaptic

Received Aug. 8, 1990; revised Nov. 21, 1990; accepted Dec. 4, 1990.

This work was supported by grants from the Deutsche Forschungsgemeinschaft (DFG), Germany, to J.D., I.P., and H. Parnas, from the Goldie Anna Trust to I.P., and from a U.S.-Israel Binational Science Foundation (BSF) grant to $H$ Parnas. I.P. is the Greenfield Professor of Neurobiology. H.L.A. was supported by a Forchheimer visiting Professorship, Hebrew University of Jerusalem.

Correspondence should be addressed to Professor 1 . Parnas at the above address. Copyright (C) 1991 Society for Neuroscience $0270-6474 / 91 / 111309-07 \$ 03.00 / 0$ currents, and distributions of quantal synaptic delays from controls and from axons cut 2 weeks to almost a year before recording.

\section{Materials and Methods}

The experiments were carried out at the Otto Loewi laboratories in the Interuniversity Institute in Eilat, Israel. Rock lobsters, Panulirus pennicillatus, were collected at the Gulf of Eilat and kept in tanks of running seawater. The lobsters were anesthetized by placing them on crushed seawater ice. Small windows $\left(1 \mathrm{~cm}^{2}\right)$ were opened in the dorsal side of abdominal segments II and III. The small nerve bundle that inncrvates the deep extensor abdominal muscles (DEAM; Parnas and Atwood, 1966) was exposed and cut, in both segments, distally to the branch leading to the superficial extensors. The 2 pieces of shell were replaced and glued with dental cement. Operated animals were kept each in a separate tank of running seawater. The lobsters were fed twice a week with tish fillets. Survival rate was higher than $50 \%$. The longest survival period so far is $1 \mathrm{yr}$. This paper is based on results obtained from 53 operated animals, with detailed computer analysis for 26 animals.

At different periods after cutting the nerve bundles, the DEAM muscles from both sides of segments I-IV were isolated with their nerves attached. The preparation was placed in a long chamber $\left(2 \times 15 \mathrm{~cm}^{2}\right)$ with a Sylgard bottom. Lobster solution circulated through a heat exchanger kept the temperature within the range of $13-15^{\circ} \mathrm{C}$. Axons in the nerve bundle were stimulated with a suction clcctrode of $60 \mu \mathrm{m}$ diameter placed over the desired axon. Because the diameter of the axons was about $50 \mu \mathrm{m}$, each axon could be stimulated separately.

Lobster solution was composed of $520 \mathrm{mM} \mathrm{NaCl}, 12 \mathrm{mM} \mathrm{KCl}, 12$ $\mathrm{mM} \mathrm{CaCl}_{2}, 10 \mathrm{mM} \mathrm{MgCl}$, and $2.5 \mathrm{~mm}$ Tris maleate. $\mathrm{PH}$ was adjusted to 7.4. For nerve stimulation, and in most experiments, $\mathrm{Ca}^{2+}$ concentration was reduced to $6 \mathrm{~mm}$, and $\mathrm{MgCl}_{2}$ concentration was increased to $30 \mathrm{~mm}$ (Parnas et al. 1984).

Synaptic currents were recorded extracellularly using the macropatch technique (Dudel, 1981). The patch electrodes, prepared from 3-mm glass capillaries, had an inner diameter of $20 \mu \mathrm{m}$ and an outer diameter of $40 \mu \mathrm{m}$. The same electrode was used for recording and for passing current, as described elsewhere (Dudel et al., 1983). When desired, $5 \times$ $10^{-7} \mathrm{M}$ tetrodotoxin (TTX) was added to block voltage-activated sodium currents. Axonal action potentials werc also recorded cxtraccllularly by placing the macropatch electrodes directly over an axon profile. Conduction velocity could be calculated from recordings of two such electrodes placed over one axon, with defined spatial separation. Recording was very specific because any slight movement of the patch electrode caused the action potential of the selected axon to be lost.

Data were digitized (Neurodata; $20 \mu \mathrm{sec} / \mathrm{bin}$ ) and stored on video cassettes. For analysis, data were fed into an Olivetti $24 \mathrm{M}$ computer. Peak amplitude, number of quanta per stimulus, and delay histograms were measured. Delay for each quantum was measured either from the negative phase of the nerve terminal current (Katz and Miledi, 1965a) or from the beginning of a brief depolarizing pulse (I. Parnas et al., 1986).

\section{Results}

\section{Description of pattern of innervation}

For the sake of clarity, a brief description of the organization of the DEAM muscles and their innervation is given. A more 


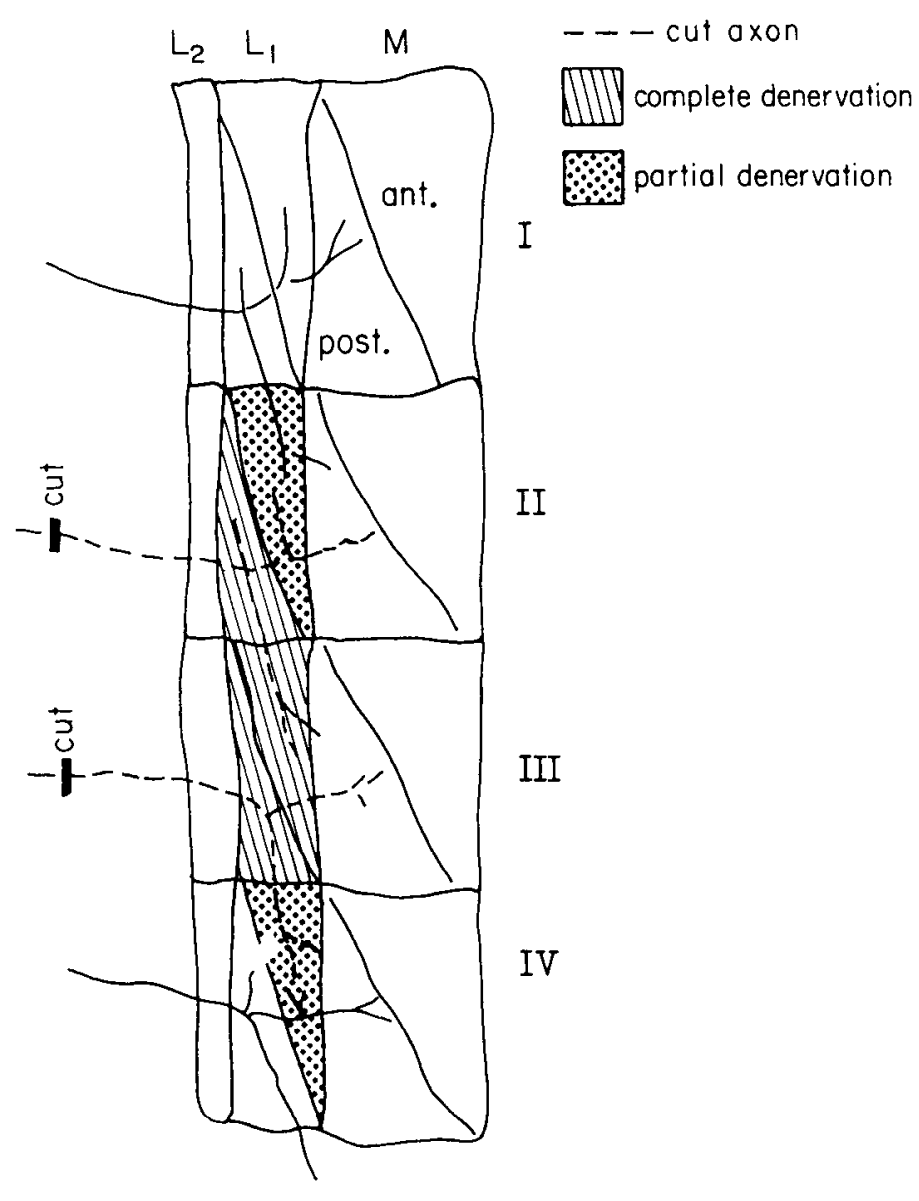

Figure 1. Scheme of the innervation pattern of abdominal segments I-IV of the DEAM: $M, L_{1}$, and $L_{2}$. The $\mathrm{L}_{1}$ muscles are each divided obliquely into an anterior (ant) and a posterior (post) bundle. Each segment receives a nerve ( 5 axons). In $\mathrm{L}_{1}$, some of the axons innervate only the posterior bundle of that particular segment and also the anterior bundle of the next inferior segment, as described in the text (see Parnas and Atwood, 1966). Regions with partial denervation and complete denervation are marked (shaded and hatched areas, respectively).

detailed description of this system and the synaptic properties of terminals of the different axons has appeared in Parnas and Atwood (1966). Each side of the DEAM muscles is composed of three muscles: the medial $(M)$ and the two lateral muscles $\left(\mathrm{L}_{1}, \mathrm{~L}_{1} ;\right.$ Fig. 1). The $\mathrm{L}_{1}$ muscle, on which experiments were performed, is divided by an oblique partition into anterior and posterior bundles. The nerve innervating these muscles contains only five axons. Each muscle, $M, L_{1}$, and $L_{2}$, is innervated by a specific excitor axon, ExM, ExL $\mathrm{L}_{1}$, and $\mathrm{ExL}_{2}$, respectively. In addition, each muscle is innervated by a common excitor (ComEx) axon and a common inhibitory (ComI) axon. Inhibition is postsynaptic only (Parnas and Atwood, 1966). The innervation pattern of the $\mathrm{L}_{1}$ muscle is of particular relevance to the present study. In each segment, the $\operatorname{ExL}_{1}$ axon innervates only the posterior bundle of the same segment, but also sends a posterior branch to innervate the anterior bundle of the next posterior segment (Fig. 1).

By cutting the nerves innervating segments II and III, we obtained the following situation: Segment I had normal innervation. In segment II, the anterior bundle had decreased innervation (Fig. 1, shaded areas), because ComEx and ComI axons had been cut, while normal innervation $\left(\mathrm{ExL}_{1}\right)$ from the pos-

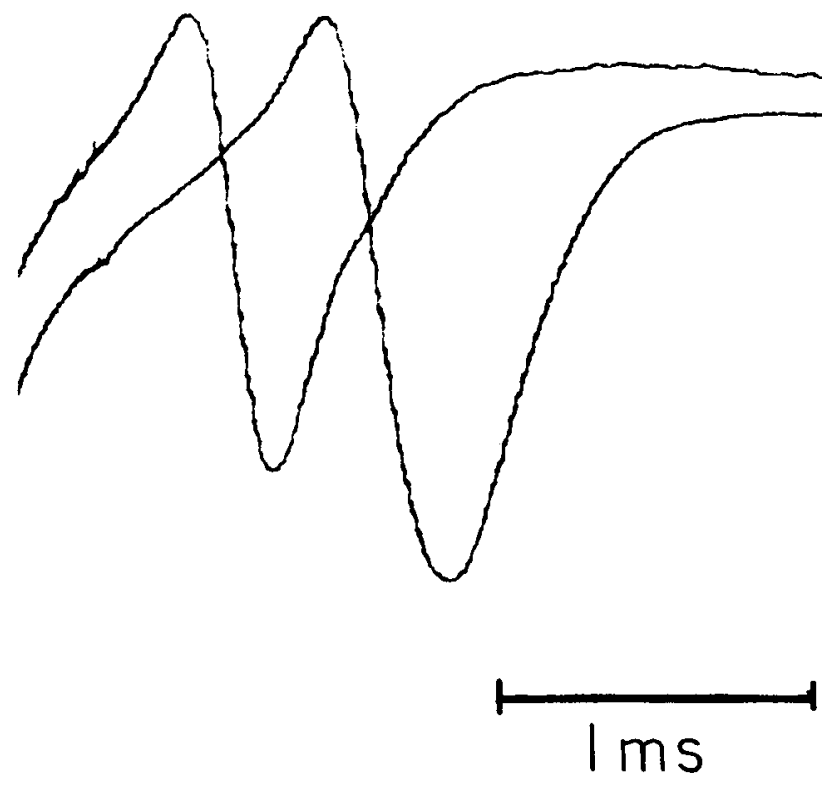

Figure 2. Measurement of conduction velocity of a decentralized axon. The axon was stimulated at the central end of the cut-off nerve segment (at almost the left-hand edge of the $L_{2}$ muscle in Fig. 1) by means of a suction electrode. Nerve action currents were recorded through 2 macropatch electrodes placed on the axon $1.5 \mathrm{~mm}$ apart. The figure shows the averages of 256 such recordings, beginning with the negative stimulus artifact. The delay from the negative phase of the first action current to that of the second one was $0.56 \mathrm{msec}$, and the resulting conduction velocity was $2.9 \mathrm{~m} / \mathrm{sec}$ at $15^{\circ} \mathrm{C}$. Nerve cut was performed 4 months before recording.

terior branch of segment I was retained. The posterior bundle of segment II sustained complete "denervation" (Fig. 1, hatched area), because all axons supplying it from the nerve entering segment II were decentralized. In segment III, complete "denervation" of both bundles was produced (Fig. 1, hatched area). In segment IV, there was decreased innervation in its anterior bundle (Fig. 1, shaded areas), with a cut posterior branch from segment III. As controls, we used the contralateral muscles as well as segment I and the posterior bundle of segment IV of the operated side.

\section{Conduction velocity of cut axons}

As mentioned in the introductory remarks, decentralized axons remain viable for at least 1 yr. Up to about 2 months after cutting the nerve, any axon or terminal found in the "denervated" region is a decentralized peripheral axon stump, because regenerated axons have not reached the muscle by this time. More than 2 months after decentralization, small axons grow into the muscle from the CNS (Atwood et al., 1989). In such preparations, an axon or synaptic site must be identified as "decentralized" or as belonging to a regenerating axon. The reinnervating axons have small diameters and, consequently, produce small action currents and show a low conduction vclocity. They could be identified by stimulating the nerve in a region central to the scar produced by cutting the nerve; synaptic potentials and nerve action potentials were recorded from the muscle. The decentralized axons studied here could never be stimulated in a region central to the scar (11 experiments).

In the nerve branch to the DEAM muscles, the axon profiles are clearly visible, and single axons could be identified and conduction velocity determined as outlined above (Materials 
$A$
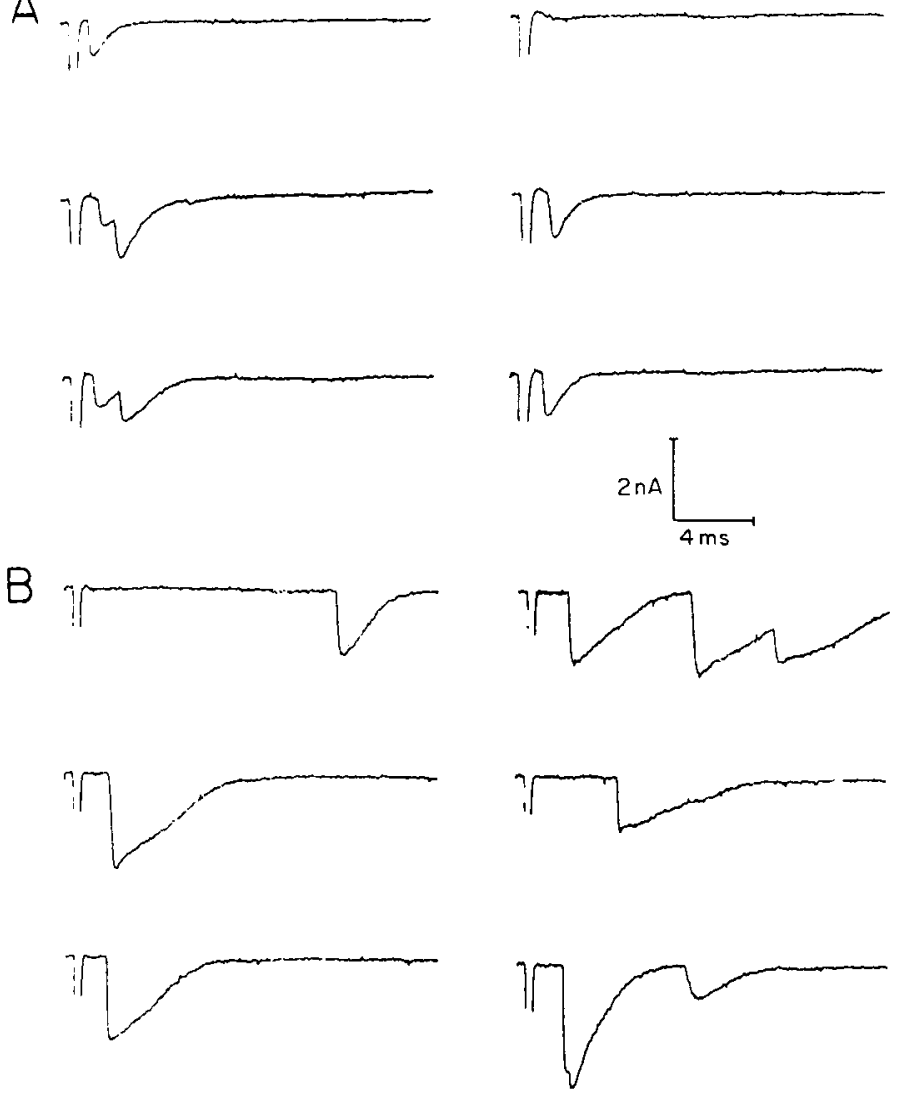

Figure 3. Sample recordings of quantal postsynaptic currents elicited by direct stimulation by pulses of $-0.5 \mu \mathrm{A}$ amplitude and $0.5 \mathrm{msec}$ duration. Each trace begins with the stimulus artifact and is followed by $0-3$ quantal responses. $A$, Controls. $B$, Recordings from the contralateral side in which the nerve was cut 2 months before recording. Note the prolonged, multiexponential decay phases.

and Methods). In controls, conduction velocity of the ComEx axon (the largest) varied between 2.8 and $3.5 \mathrm{~m} / \mathrm{sec}$. In cut axons, the range was the same. Figure 2 shows examples of action potentials recorded from the ComEx axon when the distance between the two recording electrodes was $1.5 \mathrm{~mm}$ (measured with a $50 \times$ binocular and eyepiece micrometer). The measurement was taken 4 months after the cut. Conduction velocity was $2.9 \mathrm{~m} / \mathrm{sec}$. In the other two experiments, conduction velocity was $3.0 \mathrm{~m} / \mathrm{sec}$ and $2.4 \mathrm{~m} / \mathrm{sec}$ (4 and 9 months after the cut, respectively).

\section{Postsynaptic events}

By stimulating the $\mathrm{ExL}_{1}$ axon and carefully moving the patch electrode, we were able to locate the specific release sites. We ascertained that such sites did not respond to stimulation of the ComEx axon. Once a site was located, we depolarized the terminal directly, because recording became more specific as fewer release sites were activated.

Figure 3 depicts examples of single or multiple quanta recorded in controls (Fig. 3A) or from muscle with cut axons (Fig. $3 B$ ). In this experiment, no TTX was added, and even though the nerve terminals were depolarized directly, the release was in response to an action potential. In the controls (Fig. $3 A$ ), brief quantal currents appeared immediately after the stimulus, and no late releases were seen. Their decay phase could be fit by a

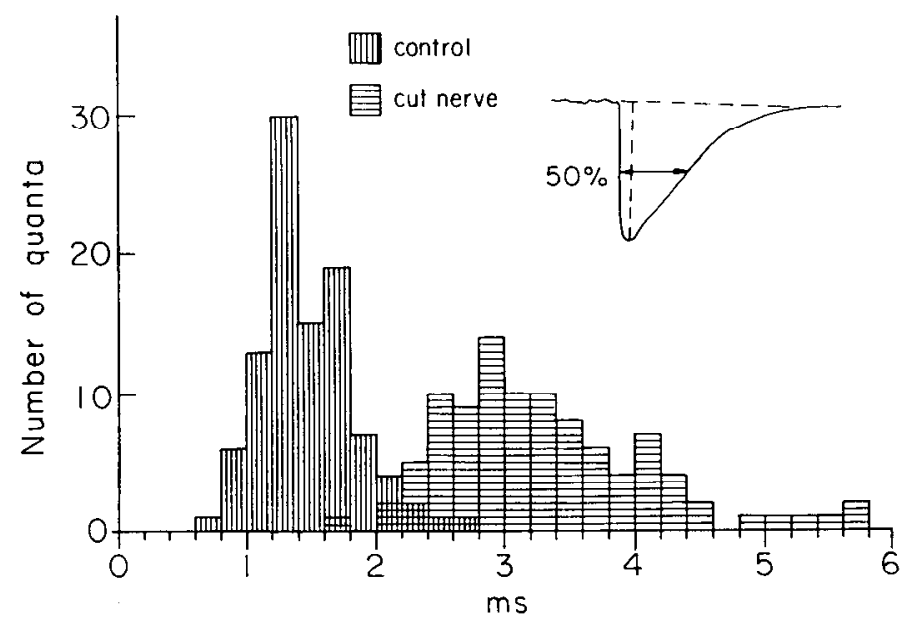

Figure 4. Distributions of the widths of quantal postsynaptic currents measured at half-maximal amplitude (inset). Abscissa, width of quantal current; ordinate, number of the responses having the width represented by the respective time bin. Vertical hatching, control; horizontal hatching, responses from a cut site 1 month after the cut. Each histogram contains values from 100 quanta.

single exponential with a time constant of about $2 \mathrm{msec}$. The quantal events from the operated side of the same animal were much slower, and their decay phase could not be fit by a single exponent. In order to quantify this observation, the widths of quantal currents in controls and "cut-nerve" preparations were measured at half amplitude. Figure 4 shows an example of such an experiment. Each histogram is composed of the first 100 consecutive single (and not multiple) quanta measured without selection. For the "cut-nerve" preparation, even though some quantal currents had a normal width, most were greatly prolonged. In the control, their duration varied between 0.6 and $2.8 \mathrm{msec}$, and in the "cut" side varied between 1.6 and $5.8 \mathrm{msec}$. This tendency applied to each of the recording sites in cut-nerve preparations. Therefore, the wide, deltoid-shaped quanta were characteristic for release sites of cut axons. Quantal events had a normal shape when recordings were made in the anterior muscle bundle of segment II, at release sites of the $\mathrm{ExL}_{1}$ axon from the posterior branch from segment I (Fig. 5, left). In the same muscle bundle, release sites of the ComEx cut axon of segment II showed "deltoid" quanta (Fig. 5, right). The change in the shape of the single quantal events became apparent 2-3 weeks after cutting the nerve. Deltoid responses were seen in preparations 7 months after the cut. At longer periods after the cut, as new regencrating axons innervated the DEAM muscles, it became more difficult to find sites of "decentralized" axons.

\section{Time course of release}

Katz and Miledi (1965b) showed that the time course of release or the probability of a quantum to be released after an impulse could be obtained from synaptic delay histograms. Figure 6 depicts synaptic delay histograms from controls $(A)$, from a preparation 2 weeks after cutting the nerve $(B)$, and from a preparation 1 month after the cut $(C)$.

In controls, the distributions of delays had a uniform shape in all synapses recorded (Fig. $6 \mathrm{~A}$ ). The minimal delay was about $1 \mathrm{msec}$. The peaks of the histograms occurred $2.5-3 \mathrm{msec}$ after the beginning of the depolarizing pulse, and phasic release declined to less than 0.1 peak level after 4-6 msec, becoming negligible after $10 \mathrm{msec}$. The rate of spontaneous release was 
Seg. I $\rightarrow$ Seg. II

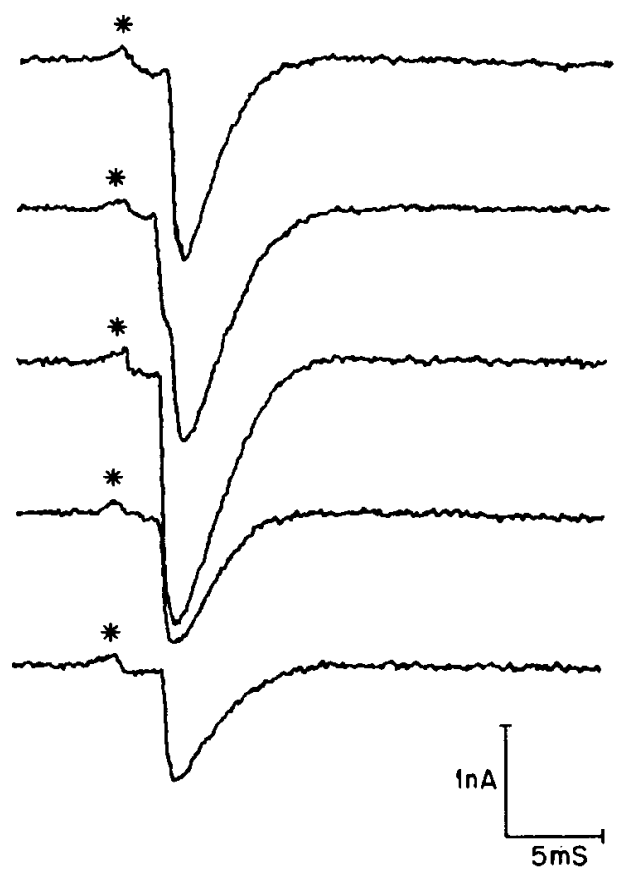

Seg. II - Seg. II
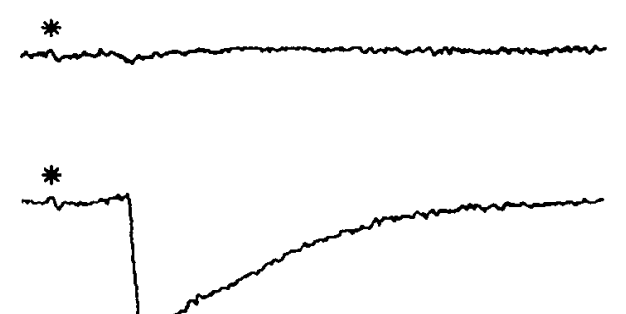

Figure 5. Sample recordings of quantal postsynaptic currents elicited by nerve stimulation in an animal in which the nerves of segments II and III were cut 3 months prior to recording. Recordings were from the anterior subbundle of segment II. Left, Stimulation of the posterior branch of the $\mathrm{ExL}_{1}$, from segment I. Note the normal brief quantal events. Right, Same bundle as at left, but a different site. Stimulation of the cut ComEx axon of segment II produced quantal events with a long decay time. Asterisks, nerve terminal potential.

very low in this preparation $(<1 / \mathrm{min})$. Such histograms were obtained from normal synapses over the past $5 \mathrm{yr}$. We never obtained release, in controls, more than $8-10 \mathrm{msec}$ after the depolarizing pulse (at $15^{\circ} \mathrm{C}$ ).

Two weeks after the cut, the distribution of delays was almost normal (Fig. 6B). The minimal delay, the peak, and the termination of release were as in the control, while more late releases may have occurred. However, by 1 month after the cut (Fig. 6C), evoked release lasted for about $20 \mathrm{msec}$ after the depolarizing pulse. Again, the minimal delay was $1 \mathrm{msec}$, and the pcak of the histogram appeared after $3 \mathrm{msec}$. Release declined to less than 0.1 of its peak level only after $10 \mathrm{msec}$. In the cut-nerve muscles, the period of release in various preparations varied from 20 to $100 \mathrm{msec}$. The late responses were not spontaneous releases. At an interval of no more than 100 msec after the stimulus, the probability of release declined to virtually 0 , the spontaneous release level. There was no indication that the rate of spontaneous release increased above control level in cut-nerve preparations.

Quantitative data from 120 recording sites are given in Table 1. On average, duration of quantal release, $d_{0.1}$ (delay at which

Table 1. Influence of decentralization of peripheral nerve on duration of release

\begin{tabular}{lccl} 
& $d_{0.1}(\mathrm{msec})$ & $\mathrm{SD}(\mathrm{msec})$ & $N$ \\
\hline Controls & 5.3 & 1.3 & 40 \\
3-4 weeks decentralized & 9.1 & 3.5 & 10 \\
1-2 months decentralized & 17.1 & 14.2 & 33 \\
2-9 months decentralized & 17.7 & 10.0 & 37
\end{tabular}

$d_{0,1}$ is the delay after the beginning of the stimulating pulse, when release dropped to less than 0.1 peak level. SD is standard deviation; $N$ is the number of recording sites. The $d_{0.1}$ values are taken from distributions of delays as in Figure 5, each containing the results of $200-2000$ stimuli (3-4 weeks: $t=3.39$, df $=48, p \leq 0.005$; 1-2 months: $t=4.91, \mathrm{df}=71, p . \leq 0.0005$ ). the release drops below 0.1 peak level), was $5 \mathrm{msec}$ in nonoperated controls. This duration increased significantly to $9 \mathrm{msec}$ (see Table 1 notes) when measured 2-4 weeks after the cutting of the ncrve. Onc month after the cut, $d_{0.1}$ reached a stable value of 17-18 msec. The prolongation of release measured by $d_{0.1}$ is highly significant (see Table 1 notes), but would have been even more impressive had the duration been determined at a lower level of release than the 0.1 peak, which would have necessitated a prohibitively large number of recordings.

\section{Effect of $T T X$}

Under many pathological conditions, the repolarization phase of action potentials becomes unstable, and sometimes "bursts" of action potentials or prolonged depolarization phases, with oscillations of the membrane potential, result. Such prolonged depolarizations or bursts of excitations could cause late releases. In order to explore this possibility, distributions of delays were measured in cut-nerve preparations with TTX blocking excitatory voltage-activated sodium currents. Figure $7, A$ and $B$, compares histograms from a (cut axon) site before and after application of $5 \times 10^{-7} \mathrm{M}$ TTX. Before TTX, the stimulus probably produced an action potential in the terminal. Late releases were seen. After TTX, the same stimulus produced less release, and the quantal content declined, but late releases were seen to the same extent as in the situation without TTX.

Doubling the $\mathrm{KCl}$ concentration, which depolarizes the nerve terminals, also did not affect the percentage of late releases (not illustrated). We can therefore conclude that depolarization of the nerve terminal is unlikely to be involved in the generation of late releases in cut-nerve preparations.

\section{Effect of hyperpolarizing postpulses}

When a depolarizing pulse is followed by a brief hyperpolarizing pulse, the quantal content of the evoked release is reduced, and, more importantly, the time course of release is shortened. This 


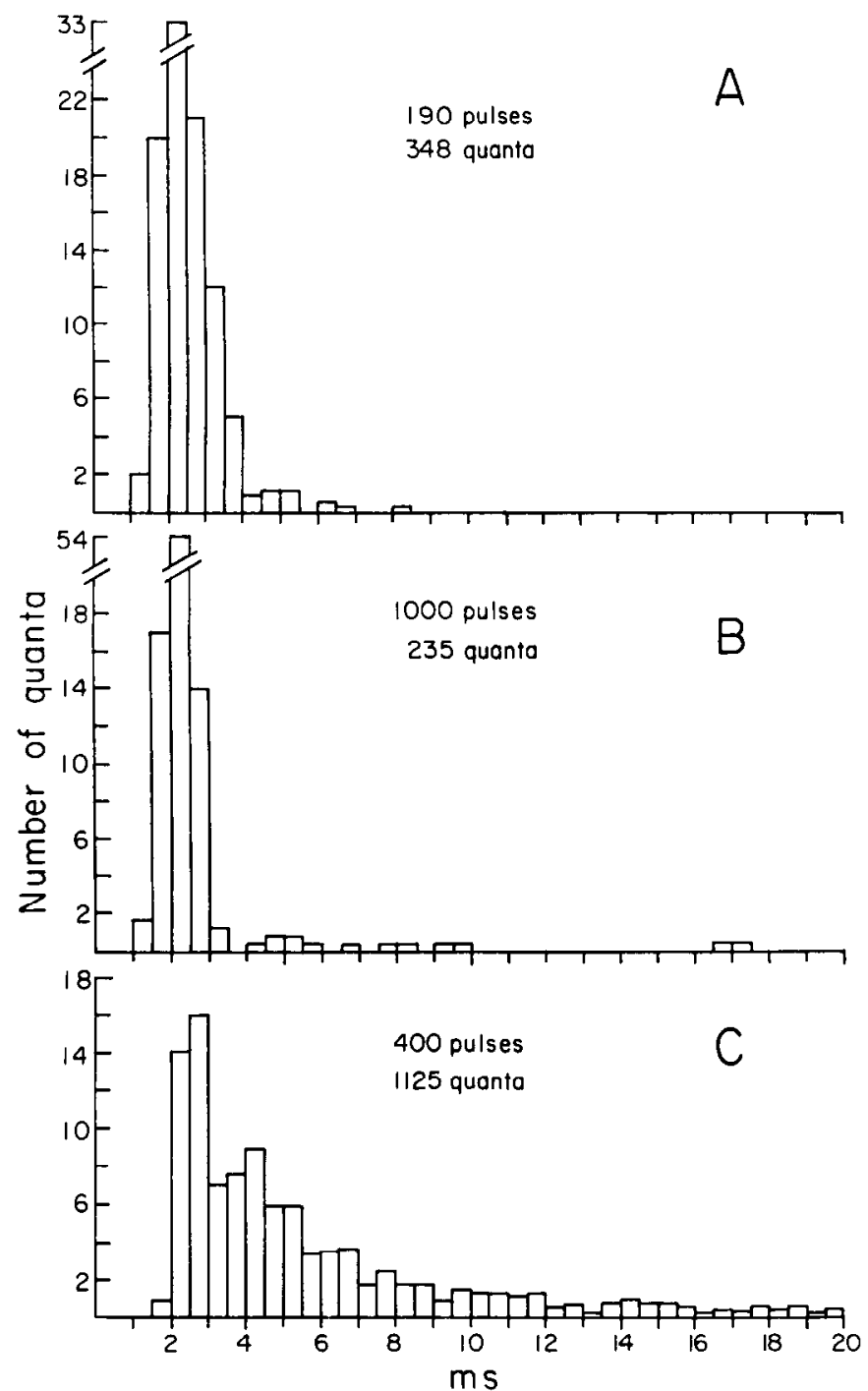

Figure 6. Distributions of delays of the beginnings of quantal currents after the start of a direct stimulus such as that in Figure 3. Abscissa, delays $(t)$; ordinate, percentage of the responses with a delay represented by the respective time bin in the abscissa. $A$, Control muscle; 348 quantal releases in response to 190 stimuli. $B$, Muscle in which the nerve was cut 2 weeks before recording; 235 quantal releases, 1000 stimuli. $C$, Muscle in which the nerve was cut 1 month before recording; 1125 quantal releases, 400 stimuli.

was shown for frog (Dudel, 1984) and crayfish (H. Parnas et al., 1986; Arechiga et al., 1990) neuromuscular systems. In controls, the normal time course of release was a few milliseconds (Fig. $6 A$ ). It was interesting to check whether, in the muscles with cut nerves and, consequently, with a longer duration of release, a hyperpolarizing postpulse would significantly shorten the generation of late releases. Such hyperpolarizing postpulses should also terminate possible depolarizing processes elicited by the stimulus. In the control, that is, with the depolarizing test pulse alone, release dropped below 0.1 of peak level after $60 \mathrm{msec}$ (Fig. 8, open bars), and the same was true with the interposition of a hyperpolarizing pulse (Fig. 8, solid bars). With the hyperpolarizing postpulse, there was a slight reduction in release immediately after the peak, as previously found for normal sites. Similar results were obtained in four experiments. The late release in the cut-nerve preparations thus seems to represent a

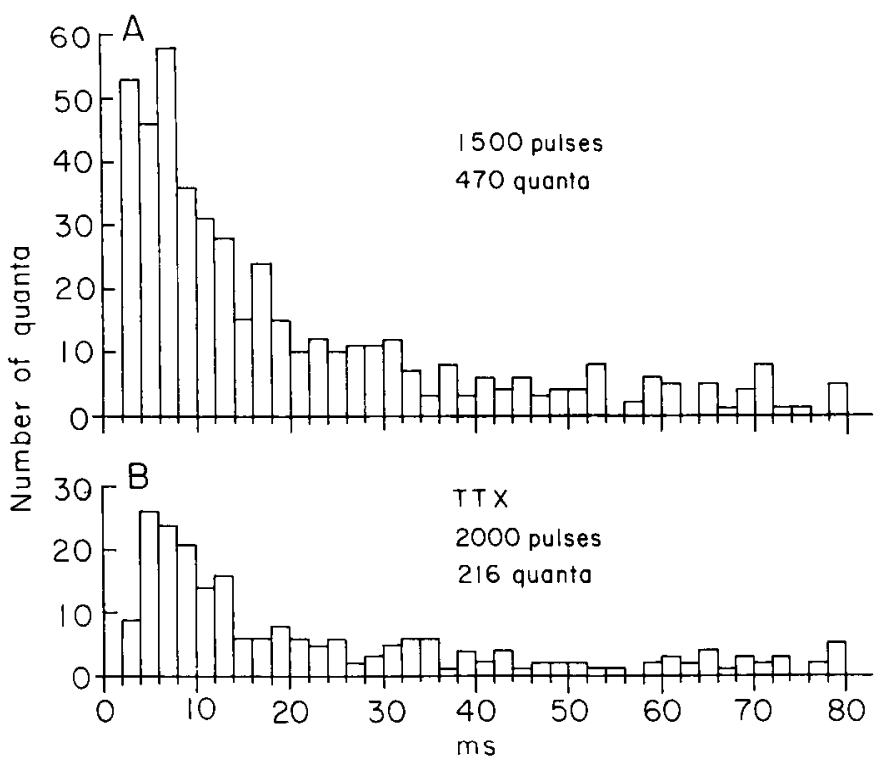

Figure 7. Distribution of quantal delays as in Figure 6, all from one recording site on a muscle in which the nerve was cut 40 days earlier. $A$, In the absence of TTX; 470 quantal releases in response to 1500 stimulus pulses. $B$, In the presence of $5 \times 10^{-7} \mathrm{M}$ TTX; 216 quantal releases, 2000 pulses.

rather autonomous process that is unaffected by de- or hyperpolarization.

\section{Discussion}

Properties of degenerating axon terminals have not previously been thoroughly investigated, to our knowledge. In vertebrates, degeneration of the distal part of severed axons is rapid, and analysis of synaptic properties has been limited to the postsynaptic receptors (Fambrough, 1979). In lobster and crayfish, the survival of the distal part of cut axons for long periods allows for a more detailed study of both presynaptic and postsynaptic changes.

In the terminals and synapses of cut axons of the lobster, we observed two main changes: One is most probably at the level of the postsynaptic receptor, the longer decay phase of the synaptic current. The second is presynaptic, the prolongation of the time course of evoked release.

The decay phase of the synaptic current, when fitted by a single exponent, is equal to the average channel burst duration (cf. Colquhoun and Sakmann, 1985; Dudel et al., 1990b). Prolongation of the average burst duration is probably not the mechanism responsible for the longer decay time of single quanta recorded at synapses of cut axons, because the decay is not monoexponential. Furthermore, in preliminary experiments with excised patches, the burst duration of single glutamatergic channels was not significantly affected in cut-nerve muscle (C. Franke, H. Hatt, O. Baranes, J. Dudel, and I. Parnas, unpublished observations). In controls, patches activated by pulses of glutamate showed complete desensitization with a time constant of about $2 \mathrm{msec}$, as in the case of the completely desensitizing glutamatergic channels of crayfish and locusts (Dudel et al., 1990a). However, analogous glutamate-pulse activation of patches from cut-nerve muscle showed incomplete desensitization, with bursts of channel openings occurring at a considerable rate as long as glutamate was present. The "humps" in the quantal currents of 


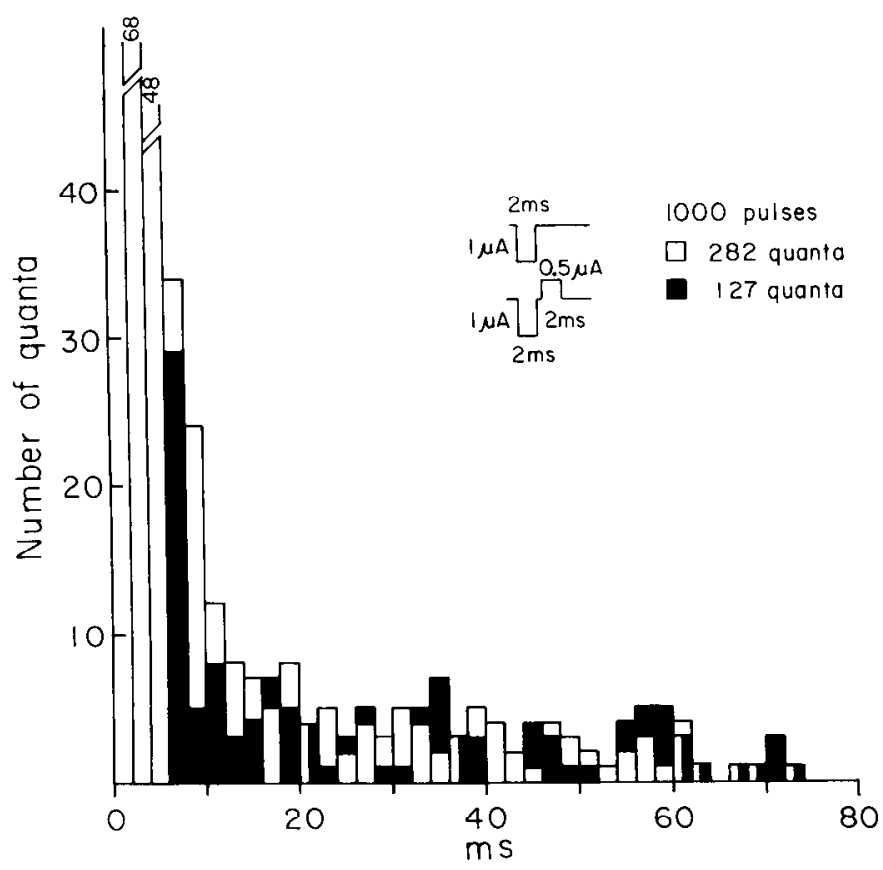

Figure 8. Distributions of delays of quantal responses as in Figure 6. Recordings are from one site in a muscle in which the nerve was cut 2 months earlier; $5 \times 10^{-7} \mathrm{M}$ TTX in bathing solution. Open bars, Control stimulus pulse of $-1 \mu \mathrm{A}, 2 \mathrm{msec} ; 282$ quantal releases to 1000 pulses. Solid bars, Stimulus pulse as in control followed after 1 msec by a hyperpolarizing pulse of $+0.5 \mu \mathrm{A}, 2 \mathrm{msec} ; 130$ quantal releases, 1000 pulses. Note that of the 282 quanta in the control, 116 appear in the period of 2-6 msec after the pulse. During this time interval, quantal events could not be recorded because of the artifact produced by the hyperpolarizing pulse. For the time between 6 and $72 \mathrm{msec}, 166$ quanta were released for the 1000 control pulses and 127 with the hyperpolarizing postpulse. Most of the block occurred at the time bins of 6-10 msec.

Figure $3 B$ may thus represent continued opening of channels, provided that a sufficient glutamate concentration is present for several milliseconds. It is interesting to note that only those receptors belonging to a cut-axon synapse showed the change in the shape of the synaptic current. Synapses of the uncut $\operatorname{ExL}_{1}$ axon from segment $I$, innervating the anterior bundle of $L_{1}$ in segment II, showed normal synaptic currents. The mechanism causing this effect is not clear.

\section{Time course of release}

The time course of release is very difficult to manipulate experimentally, at least in fast synapses such as those studied here. The time course of release was found to be independent of changes in intracellular $\mathrm{Ca}^{2+}$ concentration (Hochner et al., 1989), extracellular $\mathrm{Ca}^{2+}$ concentration (Andreu and Barrett, 1980; Datyner and Gage, 1980), and the rate of stimulation (Barrett and Stevens, 1972a,b) and of facilitation and posttetanic potentiation. On the other hand, application of $d$-tubocurarine to the frog neuromuscular junction increased the minimal delay and prolonged the time course of release (Matzner et al., 1988). The time course of release is sensitive to changes in temperature, with a $Q_{10}$ between 2 and 3 (Parnas et al., 1989). It is therefore surprising that in the synapses of cut axons the time course of release was prolonged by a factor of 10-20 while the rate of spontaneous release remained very low.

Blocking excitation by using TTX or hyperpolarizing pulses enabled us to exclude the possibility that the late releases in decentralized axons are generated by prolongation of the depolarization of the membrane during the action potential. The late releases thus reflect a basic disturbance of the release process. At present, there is no positive evidence as to the nature of this disturbance. It should be noted that the decentralized axons are cut off from the nerve cell body for months, but remain excitable, conduct action potentials, and release quanta with almost normal quantal content, even when tested by trains of thousands of stimuli. The supply of proteins necessary for these functions apparently comes from the nuclei of the incorporated satellite cells (Atwood et al., 1989). Obviously, in this curious state of a "bodyless" nerve profile, some factor or factors, which may be necessary to terminate release as rapidly and completely as in a normal axon, are missing.

\section{References}

Andreu R, Barrett EF (1980) Calcium dependence of evoked transmitter release at very low quantal contents at the frog neuromuscular junction. J Physiol (Lond) 308:79-97.

Arechiga H, Cannone A, Parnas H, Parnas I (1990) Blockage of synaptic release by brief hyperpolarizing pulses. J Physiol (Lond) 430: 119-133.

Atwood HL (1976) Organization and synaptic physiology of crustacean neuromuscular systems. Prog Neurobiol 7:291-391.

Atwood HL (1977) Crustacean neuromuscular systems: past, present and future. In: Identified neurons and behavior of arthropods (Hoyle G, ed), pp 9-29. New York: Plenum.

Atwood HL, Wojtowicz JM (1986) Short-term and long-term plasticity and physiological differentiation of crustacean motor synapses. Int Rev Neurobiol 28:275-362.

Atwood HL, Dudel J, Feinstein N, Parnas I (1989) Long term survival of decentralized axons and incorporation of satellite cells in motorneurons of rock lobster. Neurosci Lett 101:121-126.

Barrett EF, Stevens CF (1972a) Quantal independence and uniformity of presynaptic release kinetics at the frog neuromuscular junction. $\mathrm{J}$ Physiol (Lond) 227:665-689.

Barrett EF, Stevens CF (1972b) The kinetics of transmitter release at the frog neuromuscular junction. J Physiol (Lond) 227:691-708.

Bittner GD, Johnson AL (1974) Degeneration and regeneration in crustacean peripheral nerves. J Comp Physiol 89:1-21.

Colquhoun D, Sakmann B (1985) Fast events in single-channel currents activated by acetylcholinc and its analogucs at the frog muscle end-plate. J Physiol (Lond) 369:501-557.

Datyner NB, Gage PW (1980) Phasic secretion of acetylcholine at the mammalian neuromuscular junction. J Physiol (Lond) 303:299-285.

Dudel J (1981) The effect of reduced calcium on quantal unit current and release at the crayfish neuromuscular junction. Pfluegers Arch 391:35-40.

Dudel J (1984) Control of quantal transmitter release at frog's nerve terminals. II. Modulation by de- or hyperpolarizing pulses. Pfluegers Arch 402:235-243.

Dudel J, Parnas I (1987) Augmented synaptic release by one excitatory axon in regions in which a synergistic axon was removed in lobster muscle. J Physiol (Lond) 390:189-199.

Dudel J, Grossman Y, Parnas I (1981) Synaptic transmission in crustaccan muscle: cffects of elimination of the inhibitor fiber on excitatory transmission. In: Amino acid neurotransmitters (DeFeudis F, Mandel P, eds), pp 359-364. New York: Raven.

Dudel J, Parnas I, Parnas H (1983) Neurotransmitter release and its facilitation in crayfish muscle. VI. Release determined by both intracellular calcium and depolarization of the nerve terminal. Pfluegers Arch 399:1-10.

Dudel J, Franke C, Hatt H (1990a) Rapid activation, desensitization and resensitization of synaptic channels of crayfish muscle after glutamate pulses. Biophys J 57:533-545.

Dudel J, Franke C, Hatt H (1990b) A family of glutamatergic, excitatory channel types at the crayfish neuromuscular junction. J Comp Physiol A 166:757-768.

Fambrough DM (1979) Control of acetylcholine receptors in skeletal musclc. Physiol Rev 59:165-227.

Frank E (1974) The sensitivity to glutamate of denervated muscles of the crayfish. J Physiol (Lond) 242:371-382. 
Hochner B, Parnas H, Parnas I (1989) Membrane depolarization evokes neurotransmitter release in the absence of calcium entry. Nature 342 : $433-435$.

Hoy RR (1969) Degeneration and regeneration in abdominal flexor motoneurons in the crayfish. J Exp Zool 172:219-232.

Hoy RR, Bittner FD, Kennedy D (1967) Regeneration in crustacean motorneurones: evidence for axonal fusion. Science 156:251-252.

Katz B, Miledi R (1965a) The measurement of synaptic delay, and the time course of acetylcholine release at the neuromuscular junction. Proc R Soc Lond [Biol] 161:483-495.

Katz B, Miledi R (1965b) The effect of temperature on the synaptic delay at the neuromuscular junction. J Physiol (Lond) 181:656-670.

Matzner H, Parnas H, Parnas I (1988) Presynaptic effects of $d$-tubocurarine on neurotransmitter release at the neuromuscular junction of the frog. J Physiol (Lond) 398:109-121.

Parnas H, Dudel J, Parnas I (1986) Neurotransmitter release and its facilitation in crayfish. VII. Another voltage dependent process besides $\mathrm{Ca}$ entry controls the time course of phasic release. Pfluegers Arch 406:121-130.
Parnas H, Hovav G, Parnas I (1989) The effect of $\mathrm{Ca}^{2+}$ diffusion on the time course of neurotransmitter release. Biophys J 55:859-874.

Parnas I, Atwood HL (1966) Phasic and tonic neuromuscular systems in the abdominal extensor muscles of the crayfish and the rock lobster. Comp Biochem Physiol 18:701-723.

Parnas I, Bowling D (1977) Killing of single neurons by intracellular injection of proteolytic enzymes. Nature 270:626-628.

Parnas I, Dudel J, Grossman Y (1982) Chronic removal of inhibitory axon alters excitatory transmission in a crustacean muscle fiber. $J$ Neurophysiol 47:1-10.

Parnas I, Dudel J, Cohen I, Franke C (1984) Strengthening of synaptic contacts of an excitatory axon on elimination of a second excitatory axon innervating the same target. J Neurosci 4:1912-1923.

Parnas I, Parnas H, Dudel J (1986) Neurotransmitter release and its facilitation in crayfish. VIII. Modulation of release by hyperpolarizing pulses. Pfluegers Arch 406:131-137.

Rotshenker S (1988) Multiple sites and modes for regulation of axonal growth. In: Post-lesion plasticity (Flohr H, ed), pp 3-10. Berlin: Springer. 